\title{
Evaluation of Swallowing in Infants with Congenital Heart Defect
}

\author{
Karine da Rosa Pereira ${ }^{1}$ Cora Firpo ${ }^{2}$ Marisa Gasparin ${ }^{3}$ Adriane Ribeiro Teixeira ${ }^{1}$ Silvia Dornelles ${ }^{1}$ \\ Tzvi Bacaltchuk ${ }^{2}$ Deborah Salle Levy ${ }^{1}$
}

${ }^{1}$ Department of Speech Pathology, Universidade Federal do Rio Grande do Sul, Porto Alegre, Rio Grande do Sul, Brazil

2 Department of Paediatric Cardiology, Instituto de Cardiologia do Rio Grande do Sul, Porto Alegre, Rio Grande do Sul, Brazil

${ }^{3}$ Department of Speech Pathology, Instituto de Cardiologia do Rio Grande do Sul, Porto Alegre, Rio Grande do Sul, Brazil

\begin{abstract}
Address for correspondence Karine Pereira, AuD, Department of Psychology, Universidade Federal do Rio Grande do Sul, Ramiro Barcelos, 2600 Porto Alegre, Rio Grande do Sul 90035-003, Brazil (e-mail: karinedarosa@hotmail.com).
\end{abstract}

\begin{abstract}
Keywords

- congenital heart

- defects

- infant

- deglutition disorders

- respiratory aspiration

- speech

- language and hearing sciences

Introduction Surgical repair of congenital heart disease in the first years of life compromises the coordination of the suction, breathing, and swallowing functions. Objective To describe the alterations in swallowing found in infants with congenital heart defect during their hospitalization.

Methods Prospective, cross-sectional study in a reference hospital for heart disease. The sample consisted of 19 postsurgical patients who underwent an evaluation of swallowing. The infants included were younger than 7 months and had a diagnosis of congenital heart defect and suspected swallowing difficulties.

Results Of the 19 infants with congenital heart defect, the median age was 3.2 months. A significant association was found between suction rhythm and dysphagia $(p=0.036)$ and between oral-motor oral feeding readiness and dysphagia $(p=0.014)$. Conclusions The data suggest that dysphagia often occurs after surgery in infants with congenital heart defect. Infants with congenital heart defect had very similar behavior to preterm infants in terms of oral feeding readiness.
\end{abstract}

\section{Introduction}

Congenital heart defect is defined as a malformation of the heart or blood vessels that develops during the fetal period. ${ }^{1}$ The prevalence is 9:1,000 live births, corresponding to 1.35 million newborns per year. ${ }^{2}$ Most of these children require surgical intervention, often in early childhood. ${ }^{3}$

The multiple surgeries to correct the heart defect are debilitating and often hinder the quality of life. ${ }^{4}$ The presence of chromosomal abnormalities, cyanosis, and heart failure increase the complexity and challenge involved in the treatment. ${ }^{5}$ The life expectancy of patients with congenital heart defect has increased due to advances in early diagnosis, ${ }^{1,3,6}$ care after birth, and surgical techniques. ${ }^{3,6}$ However, with improved survival, new challenges have arisen in the growth and development of these children. ${ }^{6}$

In childhood, oral feeding is established as a reciprocal process, ${ }^{7}$ one that is essential in the life experience of young children. ${ }^{8}$ Swallowing is a complex process that involves neurologic and aerodigestive coordination. ${ }^{9}$ Neurobehavioral markers, such as postural control, regulation of the sleepwake cycle, and maturation of coordination of the suckswallow-breathe process, provide the clinical picture necessary for the child to advance toward oral feeding readiness. ${ }^{10}$

Newborns with congenital heart defect may require a prolonged hospital stay, well beyond the neonatal period, during the most important period of development. In the long term, this could affect somatic growth as well as cognitive and received

March 3, 2014

accepted

June 9, 2014

published online

November 5, 2014
Dol http://dx.doi.org/

10.1055/s-0034-1384687. ISSN 1809-9777.
Copyright (c) 2015 by Thieme Publicações License terms Ltda, Rio de Janeiro, Brazil 
social-emotional growth. ${ }^{6}$ Among these infants, THE nutritional condition resulting from the inability to feed often leads to an imbalance in energy intake, resulting in impaired growth. ${ }^{11}$ Due to compromised cardiopulmonary function, these infants may need a longer time to feed or may present with a lack of appetite and food refusal. ${ }^{12}$ Feeding difficulties may not be combined with oropharyngeal dysphagia. ${ }^{13}$

In pediatrics, oropharyngeal dysphagia may have a varied clinical presentation, depending on its etiology, complexity, and impact on the lives of patients with feeding difficulties. ${ }^{14}$ It is often observed in children with various medical diagnoses, ${ }^{15}$ and it may be caused by several conditions, such as cerebral palsy, cleft lip or palate, and other structural abnormalities, ${ }^{16}$ in addition to congenital heart defect. Dysphagia not only deprives one of the pleasure of eating, but also endangers health, ${ }^{17}$ because it could lead to the development of complications, including impaired growth, ${ }^{18}$ chronic aspiration, lung disease, ${ }^{18,19}$ malnutrition, ${ }^{17}$ and others.

The aim of this study was to describe the swallowing alterations found in infants with congenital heart defect evaluated during their hospitalization period.

\section{Methods}

This prospective, comparative, cross-sectional study was conducted at the Pediatric Intensive Care Unit at the Institute of Pediatric Cardiology in Porto Alegre, Brazil, from August 2011 to August 2012.

The inclusion criteria were as follows: infants under 7 months, diagnosed with congenital heart defect and with suspected swallowing disorders were included in the study. Infants with a neurologic or syndromic medical diagnosis, or awaiting surgical correction, were excluded from the research.

This study used a protocol to characterize the sample, the Preterm Oral Feeding Readiness Assessment Scale, ${ }^{20}$ and a protocol for the clinical evaluation of swallowing based on the study by Weir et al. ${ }^{21}$

The protocol for the clinical evaluation of swallowing had the following information: date of birth, gender, medical diagnosis, date of the cardiac surgery, time of the mechanical ventilation.

The Preterm Oral Feeding Readiness Assessment scale was used in this study. According to Fujinaga et al, ${ }^{22}$ this instrument is divided into five categories: (1) corrected gestational age ( $\leq 32$ weeks; 32 to 34 weeks, and $\geq 34$ weeks); (2) behavior state (state of conscience, posture, and global tonus); (3) oral posture (lips and tongue posture); (4) oral reflexes (rooting, sucking, biting, and gag reflexes); (5) nonnutritive sucking (tongue movement, tongue cupping, jaw movement, sucking strength, sucking pauses, pause per sucking, maintenance of sucking rhythm, maintenance of alertness, and stress behavioral signs). Performance in every item is graded on a scale from 0 to 2 points, with a total score that varies from 0 to 36 points. However, the first category was not considered in our study.

In this evaluation, the infants were placed on their mother's lap to assess oral posture, oral reflexes, and nonnutritive sucking. Verification of oral reflexes was performed using a gloved finger and/or a pacifier.

The clinical evaluation occurred through breast- or bottlefeeding. The infant who had previous experience of breastfeeding was evaluated at the first moment in breast-feeding, and if necessary afterward with a bottle. The first oral assessment using either bottle- or breast-feeding occurred after application of the Preterm Oral Feeding Readiness Assessment Scale. The bottle evaluated was filled with liquid and thickened liquid consistencies, and we observed coordination of sucking, swallowing, and breathing and presence of oral stasis, cough, fatigue after feeding, cyanosis, and desaturation. After swallowing evaluation, the sample was divided into two groups to compare the clinical findings for each group. The infants with normal swallowing comprise group 1 and those who had oropharyngeal dysphagia comprise group 2 .

The study was approved by the Research Ethics Committees of the Universidade Federal do Rio Grande do Sul Postgraduate Program and of Instituto de Cardiologia, under registration No. 2010064 and No. 4603/11, respectively. Consent was obtained from the guardians before the study was conducted.

The database and the analyses were performed using SPSS version 19 (Statistical Package for the Social Sciences, New York, US). Fisher exact test was used to assess the association between groups and other qualitative variables. The nonparametric Mann-Whitney test was used to compare the duration of mechanical ventilation between the groups, and the Spearman test was used to correlate oral-motor readiness with the time of mechanical ventilation. Qualitative data were described as absolute and relative values. Qualitative variables were expressed through median, minimum, and maximum values. The present study adopted a significance level of $p=0.05$.

\section{Results}

Demographic and cardiac characteristics of patients are shown in - Table 1. Out of the 19 infants in the sample, 11 (58\%) were boys. The median age was 3.2 months (minimum $=0.3$, maximum $=6.2$ ). Twelve infants had acyanotic congenital heart defect, and seven had cyanotic congenital heart defect.

Oropharyngeal dysphagia was identified in $16(84 \%)$ of the infants under study. The most common clinical finding was the lack of suck-swallow-breathe coordination $(p \leq .001)$, which was observed in combination with oral leaking in 5 infants; stasis in the oral cavity in 4; cough during feeding in 5 ; fatigue during feeding in 4; desaturation in 3 ; and cyanosis during feeding in 1. Descriptions of the clinical evaluation and score for Preterm Oral Feeding Readiness Assessment Scale are described in - Table 2 .

During the evaluation of readiness for oral feeding, no association was found between absence of sucking rhythm and the presence of oropharyngeal dysphagia $(p=0.036)$. However, 12 (63\%) infants with oropharyngeal dysphagia presented arrhythmic sucking, and all infants with normal swallowing presented rhythmic sucking. There was no relation of sucking/pause and dysphagia between the groups. The comparative distribution between the two groups, regarding the variables, is shown in - Table 3 . 
Table 1 Demographic characteristics of cardiac patients

\begin{tabular}{|c|c|c|c|c|c|c|c|}
\hline Case no. & Gender & Age & Cardiac diagnosis & $\begin{array}{l}\text { Type of } \\
\text { cardiology }\end{array}$ & $\begin{array}{l}\text { Surgical } \\
\text { repair }\end{array}$ & $\begin{array}{l}\text { Intubation } \\
\text { time (h) }\end{array}$ & $\begin{array}{l}\text { Extubation } \\
\text { failed }\end{array}$ \\
\hline 1 & $\mathrm{~F}$ & 5 mo $1 \mathrm{~d}$ & $\begin{array}{l}\text { Complex cyanotic congenital heart } \\
\text { disease }\end{array}$ & Cyanotic & Yes & 1,536 & Yes \\
\hline 2 & $\mathrm{~F}$ & $28 \mathrm{~d}$ & Pulmonary stenosis & Acyanotic & Yes & 456 & Yes \\
\hline 3 & $\mathrm{~F}$ & $6 \mathrm{mo} 7 \mathrm{~d}$ & Interventricular communication & Acyanotic & Yes & 4 & No \\
\hline 4 & $\mathrm{~F}$ & $4 \mathrm{mo} 2 \mathrm{~d}$ & Aortic stenosis & Acyanotic & Yes & 2.5 & No \\
\hline 5 & M & 3 mo $9 d$ & Aortic coarctation & Acyanotic & Yes & 24 & No \\
\hline 6 & M & $3 \mathrm{mo} 2 \mathrm{~d}$ & $\begin{array}{l}\text { Total anomalous pulmonary venous } \\
\text { drainage }\end{array}$ & Acyanotic & Yes & 48 & Yes \\
\hline 7 & M & $20 \mathrm{~d}$ & Aortic coarctation and aortic stenosis & Acyanotic & Yes & 144 & No \\
\hline 8 & M & $19 \mathrm{~d}$ & Aortic stenosis & Acyanotic & Yes & 336 & Yes \\
\hline 9 & M & $3 \mathrm{mo} 3 \mathrm{~d}$ & $\begin{array}{l}\text { Pulmonary atresia and atrial septal } \\
\text { defects }\end{array}$ & Cyanotic & Yes & 216 & Yes \\
\hline 10 & $\mathrm{M}$ & $4 \mathrm{mo} 2 \mathrm{~d}$ & $\begin{array}{l}\text { Atrial septal defects, interventricular } \\
\text { communication and aortic } \\
\text { coarctation }\end{array}$ & Acyanotic & Yes & 960 & Yes \\
\hline 11 & $\mathrm{M}$ & $15 \mathrm{~d}$ & Transposition of great vessels & Cyanotic & Yes & 9 & No \\
\hline 12 & M & $4 \mathrm{mo} 17 \mathrm{~d}$ & Interventricular communication & Acyanotic & Yes & 192 & No \\
\hline 13 & $\mathrm{~F}$ & $10 \mathrm{~d}$ & Aortic stenosis & Acyanotic & Yes & 24 & No \\
\hline 14 & $\mathrm{M}$ & $5 \mathrm{mo} 25 \mathrm{~d}$ & $\begin{array}{l}\text { Interventricular communication, } \\
\text { patent ductus arteriosus, and } \\
\text { aortic coarctation }\end{array}$ & Acyanotic & Yes & 288 & Yes \\
\hline 15 & $\mathrm{~F}$ & $15 d$ & Pulmonary atresia & Cyanotic & Yes & 168 & No \\
\hline 16 & M & $2 \mathrm{mo} 10 \mathrm{~d}$ & $\begin{array}{l}\text { Atrial septal defects, interventricular } \\
\text { communication, and patent ductus } \\
\text { arteriosus }\end{array}$ & Acyanotic & Yes & 48 & No \\
\hline 17 & $\mathrm{~F}$ & $4 \mathrm{mo} 24 \mathrm{~d}$ & Tetralogy of Fallot & Cyanotic & Yes & 24 & No \\
\hline 18 & M & $16 \mathrm{~d}$ & Transposition of great vessels & Cyanotic & Yes & 168 & No \\
\hline 19 & $\mathrm{~F}$ & $4 \mathrm{mo}$ & Tetralogy of Fallot & Cyanotic & Yes & 648 & Yes \\
\hline
\end{tabular}

The group of infants with normal swallowing and the group with oropharyngeal dysphagia had a median 24 and 48 hours in mechanical ventilation, respectively. There was no correlation between the duration of mechanical ventilation and the oral readiness score. Spearman correlation was $r \leq-349$.

- Fig. 1 shows a comparison of performance in the readiness for oral feeding protocol between the group of infants who had normal swallowing and the group of infants who had oropharyngeal dysphagia. The group of infants with normal swallowing had a median score of 33 (minimum $=30$, maximum $=36$ ) and the group of infants with oropharyngeal dysphagia had a median score of 25 (minimum $=16$, maximum $=33$ ). The correlation between oral-motor readiness and dysphagia was $p=0.014$.

\section{Discussion}

The present study showed that infants with congenital heart defect have low scores on the evaluation of readiness for oral feeding, which are very close to those of preterm infants. ${ }^{22}$ It should be underscored that the evaluation of readiness for preterm infants differs from the evaluation of infants with congenital heart defect, because the coordination of the suck-swallow-breathe process improves with the maturation of the central nervous system in cases of preterm birth. $^{23}$

The mean values for the oral-motor readiness scores found in this survey were 25 for the group of infants with oropharyngeal dysphagia and 33 for the group of infants with normal swallowing. These results show that oral-motor skill is associated with oropharyngeal dysphagia and that the assessment of readiness before clinical evaluation is extremely important.

By exploring possible variables that could affect the performance of swallowing, we found that the duration of mechanical ventilation did not influence the oral-motor readiness or the outcome of the clinical evaluation. This finding diverges from the literature, which states that oropharyngeal dysphagia may occur after mechanical ventilation $^{24}$ and after prolonged intubation. ${ }^{25}$ 
58 Swallowing in Infants with Congenital Heart Defect Pereira et al.

Table 2 Clinical evaluation and score of infants in the Preterm Oral Feeding Readiness Assessment scale

\begin{tabular}{|c|c|c|c|c|c|}
\hline Case no. & Consistencies & Utensils & Clinical findings & Result & Score \\
\hline 1 & Liquid thickened & $\begin{array}{l}\text { Latex nipple, orthodontic nipple, } \\
\text { conventional flow (milk hole) }\end{array}$ & $\begin{array}{l}\text { Incoordination of suck, } \\
\text { swallow, and respiration }\end{array}$ & Oropharyngeal dysphagia & 20 \\
\hline 2 & Liquid & Breast-feeding & $\begin{array}{l}\text { Incoordination of suck, } \\
\text { swallow, and respiration; } \\
\text { desaturation fatigue }\end{array}$ & Oropharyngeal dysphagia & 23 \\
\hline 3 & Liquid thickened & $\begin{array}{l}\text { Latex nipple, orthodontic nipple, } \\
\text { reduced flow (water/tea hole) }\end{array}$ & $\begin{array}{l}\text { Incoordination of suck, } \\
\text { swallow, and respiration }\end{array}$ & Oropharyngeal dysphagia & 25 \\
\hline 4 & Liquid & $\begin{array}{l}\text { Silicone nipple, orthodontic nipple, } \\
\text { conventional flow (milk hole) }\end{array}$ & $\begin{array}{l}\text { Incoordination of suck, } \\
\text { swallow, and respiration; } \\
\text { cough fatigue }\end{array}$ & Oropharyngeal dysphagia & 30 \\
\hline 5 & Liquid thickened & $\begin{array}{l}\text { Silicone nipple, conventional nipple, } \\
\text { conventional flow (milk hole) }\end{array}$ & $\begin{array}{l}\text { Incoordination of suck, } \\
\text { swallow, and respiration }\end{array}$ & Oropharyngeal dysphagia & 33 \\
\hline 6 & Liquid & $\begin{array}{l}\text { Breast-feeding; silicone nipple, or- } \\
\text { thodontic nipple, conventional flow } \\
\text { (milk hole) }\end{array}$ & $\begin{array}{l}\text { Incoordination of suck, } \\
\text { swallow, and respiration; oral } \\
\text { spillage; cough }\end{array}$ & Oropharyngeal dysphagia & 25 \\
\hline 7 & Liquid & $\begin{array}{l}\text { Silicone nipple, conventional nipple, } \\
\text { conventional flow (milk hole) }\end{array}$ & $\begin{array}{l}\text { Incoordination of suck, } \\
\text { swallow, and respiration }\end{array}$ & Oropharyngeal dysphagia & 33 \\
\hline 8 & Liquid & $\begin{array}{l}\text { Latex nipple, orthodontic nipple, } \\
\text { conventional flow (milk hole) }\end{array}$ & $\begin{array}{l}\text { Incoordination of suck, } \\
\text { swallow, and respiration }\end{array}$ & Oropharyngeal dysphagia & 28 \\
\hline 9 & Liquid & $\begin{array}{l}\text { Silicone nipple, conventional nipple, } \\
\text { conventional flow (milk hole) }\end{array}$ & $\begin{array}{l}\text { Incoordination of suck, } \\
\text { swallow, and respiration; } \\
\text { stasis in the oral cavity; } \\
\text { cyanosis }\end{array}$ & Oropharyngeal dysphagia & 22 \\
\hline 10 & Liquid thickened & $\begin{array}{l}\text { Latex nipple, orthodontic nipple, } \\
\text { conventional flow (milk hole) }\end{array}$ & $\begin{array}{l}\text { Incoordination of suck, } \\
\text { swallow, and respiration; } \\
\text { fatigue }\end{array}$ & Oropharyngeal dysphagia & 25 \\
\hline 11 & Liquid thickened & $\begin{array}{l}\text { Latex nipple, conventional nipple, } \\
\text { conventional flow (milk hole) }\end{array}$ & $\begin{array}{l}\text { Desaturation Incoordination } \\
\text { of suck, swallow, and } \\
\text { respiration; fatigue; stasis } \\
\text { in the oral cavity }\end{array}$ & Oropharyngeal dysphagia & 16 \\
\hline 12 & Liquid & $\begin{array}{l}\text { silicone nipple, conventional nipple, } \\
\text { conventional flow (milk hole) }\end{array}$ & $\begin{array}{l}\text { Incoordination of suck, } \\
\text { swallow, and respiration; oral } \\
\text { spillage; cough }\end{array}$ & Oropharyngeal dysphagia & 29 \\
\hline 13 & Liquid & $\begin{array}{l}\text { Latex nipple, conventional nipple, } \\
\text { conventional flow (milk hole) }\end{array}$ & $\begin{array}{l}\text { Incoordination of suck, } \\
\text { swallow, and respiration; oral } \\
\text { spillage; cough }\end{array}$ & Oropharyngeal dysphagia & 29 \\
\hline 14 & Liquid & Breast-feeding & - & Normal swallowing & 30 \\
\hline 15 & Liquid & $\begin{array}{l}\text { Latex nipple, conventional nipple, } \\
\text { conventional flow (milk hole) }\end{array}$ & $\begin{array}{l}\text { Incoordination of suck, } \\
\text { swallow, and respiration; } \\
\text { stasis in the oral cavity oral } \\
\text { spillage }\end{array}$ & Oropharyngeal dysphagia & 25 \\
\hline 16 & Liquid & Breast-feeding & $\begin{array}{l}\text { Incoordination of suck, } \\
\text { swallow, and respiration }\end{array}$ & Oropharyngeal dysphagia & 24 \\
\hline 17 & Liquid & Breast-feeding & - & Normal swallowing & 36 \\
\hline 18 & Liquid & Breast-feeding & - & Normal swallowing & 33 \\
\hline 19 & Liquid thickened & $\begin{array}{l}\text { Silicone nipple, conventional nipple, } \\
\text { conventional flow (milk hole) }\end{array}$ & $\begin{array}{l}\text { Incoordination of suck, } \\
\text { swallow, and respiration; } \\
\text { stasis in the oral cavity; } \\
\text { oral spillage }\end{array}$ & Oropharyngeal dysphagia & 23 \\
\hline
\end{tabular}

Clinical evaluation showed that in infants with congenital heart defect, oropharyngeal dysphagia is characterized by a lack of coordination of the suck-swallow-breathe process, whether or not this is combined with stasis of food in the oral cavity, cough, anterior leaking, and fatigue during breastfeeding. It is known that oropharyngeal dysphagia may occur in young children due to fatigue of the swallowing mechanism. ${ }^{25}$ Moreover, oral feeding requires muscle strength to extract the milk from the bottle or from the mother's breast and coordination of the suck-swallow-breathe process; also, infants with congenital heart defect are likely to resist ingesting the total prescribed volume, due to surgical intervention, which hinders weight gain and growth of these newborns and infants. $^{26}$

Among the pediatric population with heart disease, risk factors for oropharyngeal dysphagia as follows: age under 3 years, preoperative intubation, intubation greater than 7 days, and operations for obstructive injuries on the left side. The use of transesophageal echocardiography in children weighing less than $5.5 \mathrm{~kg}$ is considered a predictor of 
Table 3 Comparative distribution of the variables between the two groups

\begin{tabular}{|c|c|c|c|}
\hline & Group 1 & Group 2 & $p$ value $^{a}$ \\
\hline Male & $2(18 \%)$ & $9(82 \%)$ & $>0.999$ \\
\hline Acyanotic heart defect & $1(33 \%)$ & $11(58 \%)$ & 0.422 \\
\hline Arrhythmic suction & $0(0 \%)$ & $12(75 \%)$ & 0.036 \\
\hline$<5$ sucks/pause & $0(0 \%)$ & $6(37.5 \%)$ & \multirow[t]{3}{*}{0.427} \\
\hline 5-8 sucks/pause & $1(33 \%)$ & $4(25 \%)$ & \\
\hline$>8$ sucks/pause & $2(67 \%)$ & $6(37.5 \%)$ & \\
\hline Strong suck & $3(100 \%)$ & $8(50 \%)$ & \multirow[t]{2}{*}{0.228} \\
\hline Weak suck & $0(0 \%)$ & $8(50 \%)$ & \\
\hline $\begin{array}{l}\text { Lack of suck, swallow, } \\
\text { respiration coordination }\end{array}$ & $0(0 \%)$ & $16(100 \%)$ & $<0.001$ \\
\hline Cough & $0(0 \%)$ & $5(31.3 \%)$ & 0.278 \\
\hline
\end{tabular}

Note: group 1, infants with no alterations in swallowing; group 2, infants with alterations in swallowing.

${ }^{\mathrm{a}}$ Fisher exact test.

dysphagia. ${ }^{27}$ However, clinical evidence of oropharyngeal dysphagia in infants investigated postoperatively in this research emphasizes that dysphagia may take place with intubation times of less than 7 days.

Kohr et al aimed to determine the incidence and risk factors for oropharyngeal dysphagia in children after cardiac surgery and found that oropharyngeal dysphagia occurred in 9 (18\%) of the 50 patients. ${ }^{27}$ The videofluoroscopic findings were as follows: 7 (78\%) cases of delayed triggering of swallowing; 2 (22\%) cases of laryngeal penetration, with direct aspiration and vocal fold paralysis; 2 (22\%) cases of occasional laryngeal penetration without aspiration; 1 (11\%) case of laryngeal reduction; and 2 (22\%) cases of direct

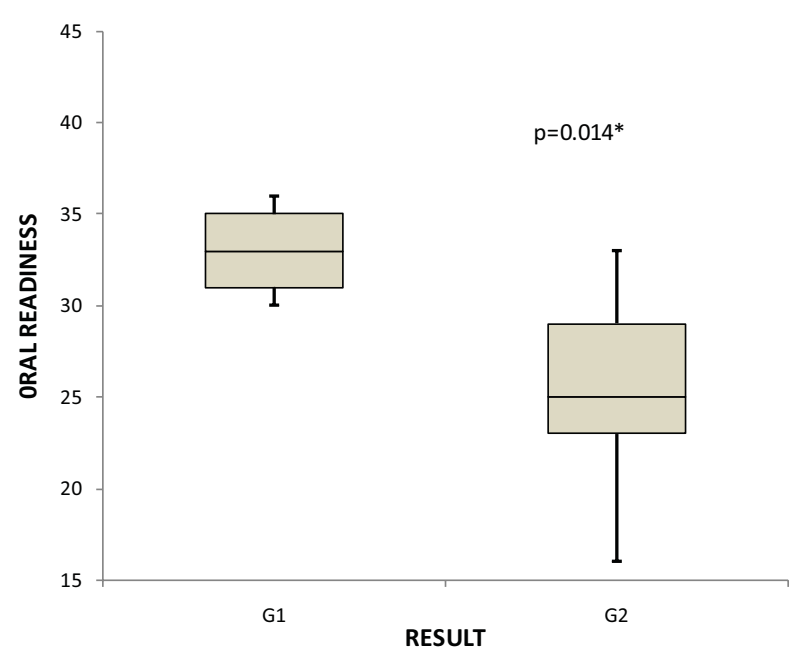

Fig. 1 Comparison between the groups of infants with congenital heart defect, according to the preterm readiness for oral feeding protocol. Abbreviations: G1, group 1 (infants with no alterations in swallowing); G2, group 2 (infants with alterations in swallowing). *Mann-Whitney test. aspiration resulting from vocal fold paralysis. Sachdeva et $\mathrm{al}^{28}$ whose objective was to evaluate the impact of voice disorders and feeding in children after cardiac surgery, showed that swallowing dysfunction was observed in 34 (89\%) children with vocal fold alterations. The swallowing examination was performed in 29 patients with congenital heart defects, $\sim 30$ days after surgery. The most common pathophysiological finding was aspiration, which was observed in 23 (80\%) children. Laryngeal penetration occurred in 5 of them (17\%), and delayed triggering of swallowing in only 1 (3\%). Through instrumental evaluation, researchers were able to identify oropharyngeal dysphagia in this population of children with congenital heart defects.

Yi et al performed a retrospective study in which the objective was to evaluate the prevalence and clinical predictors of dysphagia and determine the videofluoroscopic findings of swallowing in children who underwent cardiac surgery. ${ }^{29}$ Through videofluoroscopic findings, the authors concluded that $67.9 \%$ of the children had laryngeal penetration and $63.6 \%$ had tracheal aspiration, and of these $85.7 \%$ of symptoms were silent, without the presence of cough. In our clinical study, we also observed a low incidence of cough during swallowing. Only 4 of the 16 infants identified with oropharyngeal dysphagia showed cough while swallowing.

Our results corroborate the studies by Kohr et al, ${ }^{27}$ Sachdeva et al, ${ }^{28}$ and Yi et al, ${ }^{29}$ which showed that oropharyngeal dysphagia often occurs postoperatively in infants, as most infants who had corrective surgery presented oropharyngeal dysphagia, even with thickened liquid. Thickening of food is a procedure adopted to minimize the pattern of dysphagia. ${ }^{27}$

It is important to note that feeding problems are common among children with congenital heart defect. $6,11,27-31$ According to Arvedson, ${ }^{13}$ feeding difficulties are characterized by refusal, disruptive behavior, preference, and lack of feeding competence expected for the subjects' level of development. Newborns who were born with a serious heart condition requiring heart surgery in the first month of life have a high risk of presenting feeding difficulties until 2 years of age. ${ }^{30}$ The speech therapist should be aware of these behaviors during the evaluation of swallowing.

The results of the present study suggest that dysphagia often occurs in infants after corrective surgery for congenital heart condition. The use of the preterm readiness for an oral feeding protocol enabled us to verify that infants with congenital heart defect may present with very similar behavior to those of preterm newborns.

\section{Conclusion}

In the present study, the occurrence of oropharyngeal dysphagia in infants under 7 months of age with congenital heart defect was observed, and the same finding was detected by clinical evaluation. Infants with congenital heart defect showed a very similar behavior to that of preterm newborns. However, oropharyngeal dysphagia is a variable that still needs to be further studied to determine the epidemiologic data and identify the best clinical management outcome among this population. 


\section{References}

1 Teixeira FM, Coelho RM, Proença C, et al. Quality of life experienced by adolescents and young adults with congenital heart disease. Pediatr Cardiol 2011;32(8):1132-1138

2 van der Linde D, Konings EE, Slager MA, et al. Birth prevalence of congenital heart disease worldwide: a systematic review and meta-analysis. J Am Coll Cardiol 2011;58(21):2241-2247

3 Gerdes M, Flynn T. Clinical assessment of neurobehavioral outcomes in infants and children with congenital heart disease. Progress in Pediatr Cardiol 2010;29(2):97-105

4 Bruneau BG. The developmental genetics of congenital heart disease. Nature 2008;451(7181):943-948

5 Medoff-Cooper B, Naim M, Torowicz D, Mott A. Feeding, growth, and nutrition in children with congenitally malformed hearts. Cardiol Young 2010;20(3, Suppl 3):149-153

6 Sables-Baus S, Kaufman J, Cook P, da Cruz EM. Oral feeding outcomes in neonates with congenital cardiac disease undergoing cardiac surgery. Cardiol Young 2012;22(1):42-48

7 Delaney AL, Arvedson JC. Development of swallowing and feeding: prenatal through first year of life. Dev Disabil Res Rev 2008;14(2): 105-117

8 Newman LA, Keckley C, Petersen MC, Hamner A. Swallowing function and medical diagnoses in infants suspected of dysphagia. Pediatrics 2001;108(6):E106

9 Weckmueller J, Easterling C, Arvedson J. Preliminary temporal measurement analysis of normal oropharyngeal swallowing in infants and young children. Dysphagia 2011;26(2):135-143

10 Silberstein D, Geva R, Feldman R, et al. The transition to oral feeding in low-risk premature infants: relation to infant neurobehavioral functioning and mother-infant feeding interaction. Early Hum Dev 2009;85(3):157-162

11 Jadcherla SR, Vijayapal AS, Leuthner S. Feeding abilities in neonates with congenital heart disease: a retrospective study. J Perinatol 2009;29(2):112-118

12 Woodward CS. Keeping children with congenital heart disease healthy. J Pediatr Health Care 2011;25(6):373-378

13 Arvedson JC. Assessment of pediatric dysphagia and feeding disorders: clinical and instrumental approaches. Dev Disabil Res Rev 2008;14(2):118-127

14 Arvedson J, Clark H, Lazarus C, Schooling T, Frymark T. The effects of oral-motor exercises on swallowing in children: an evidencebased systematic review. Dev Med Child Neurol 2010;52(11): 1000-1013

15 Sitton M, Arvedson J, Visotcky A, et al. Fiberoptic endoscopic evaluation of swallowing in children: feeding outcomes related to diagnostic groups and endoscopic findings. Int J Pediatr Otorhinolaryngol 2011;75(8):1024-1031

16 Heiss CJ, Goldberg L, Dzarnoski M. Registered dietitians and speechlanguage pathologists: an important partnership in dysphagia management. J Am Diet Assoc 2010;110(9):1290, 1292-1293
17 Hongama S, Nagao K, Toko S, et al. MI sensor-aided screening system for assessing swallowing dysfunction: application to the repetitive saliva-swallowing test. J Prosthodont Res 2012;56(1): 53-57

18 Hewetson R, Singh S. The lived experience of mothers of children with chronic feeding and/or swallowing difficulties. Dysphagia 2009;24(3):322-332

19 Christiaanse ME, Mabe B, Russell G, Simeone TL, Fortunato J, Rubin B. Neuromuscular electrical stimulation is no more effective than usual care for the treatment of primary dysphagia in children. Pediatr Pulmonol 2011;46(6):559-565

20 Fujinaga CI, Scochi CGS, Santos CB, et al. Validação do conteúdo de um instrumento para avaliação da prontidão do prematuro para início da alimentação oral. Rev Bras Saude Mater Infant 2008;8(4): 391-399

21 Weir K, McMahon S, Barry L, Masters IB, Chang AB. Clinical signs and symptoms of oropharyngeal aspiration and dysphagia in children. Eur Respir J 2009;33(3):604-611

22 Fujinaga CI, de Moraes SA, Zamberlan-Amorim NE, Castral TC, de Almeida e Silva A, Scochi CG. Clinical validation of the Preterm Oral Feeding Readiness Assessment Scale. Rev Lat Am Enfermagem 2013;21(Spec No):140-145

23 Mizuno K, Ueda A. The maturation and coordination of sucking, swallowing, and respiration in preterm infants. J Pediatr 2003; 142(1):36-40

24 Brown CV, Hejl K, Mandaville AD, Chaney PE, Stevenson G, Smith C. Swallowing dysfunction after mechanical ventilation in trauma patients. J Crit Care 2011;26(1):e9-e13

25 Bordon A, Bokhari R, Sperry J, Testa D IV, Feinstein A, Ghaemmaghami V. Swallowing dysfunction after prolonged intubation: analysis of risk factors in trauma patients. Am J Surg 2011; 202(6):679-682, discussion 682-683

26 Tutor JD, Gosa MM. Dysphagia and aspiration in children. Pediatr Pulmonol 2012;47(4):321-337

27 Kohr LM, Dargan M, Hague A, et al. The incidence of dysphagia in pediatric patients after open heart procedures with transesophageal echocardiography. Ann Thorac Surg 2003;76(5):1450-1456

28 Sachdeva R, Hussain E, Moss MM, et al. Vocal cord dysfunction and feeding difficulties after pediatric cardiovascular surgery. J Pediatr 2007;151(3):312-315, e1-e2

29 Yi SH, Kim SJ, Huh J, Jun TG, Cheon HJ, Kwon JY. Dysphagia in infants after open heart procedures. Am J Phys Med Rehabil 2013; 92(6):496-503

30 Medoff-Cooper B, Irving SY. Innovative strategies for feeding and nutrition in infants with congenitally malformed hearts. Cardiol Young 2009;19(Suppl 2):90-95

31 Maurer I, Latal B, Geissmann H, Knirsch W, Bauersfeld U, Balmer C. Prevalence and predictors of later feeding disorders in children who underwent neonatal cardiac surgery for congenital heart disease. Cardiol Young 2011;21(3):303-309 